\title{
EMOTIONAL DYSREGULATION AND ATTACHMENT DIMENSIONS IN FEMALE PATIENTS WITH BULIMIA NERVOSA
}

\author{
Trpimir Jakovina ${ }^{1}$, Maja Crnković Batista ${ }^{2}$, Andrea Ražić Pavičić ${ }^{1,3}$, \\ Iva Žurić Jakovina ${ }^{4}$ \& Ivan Begovac ${ }^{1,3}$ \\ ${ }^{l}$ Department of Psychological Medicine, University Hospital Centre Zagreb, Zagreb, Croatia \\ ${ }^{2}$ Department of Pediatrics, Clinical Hospital Center Sestre milosrdnice, Zagreb, Croatia \\ ${ }^{3}$ School of Medicine, University of Zagreb, Zagreb, Croatia \\ ${ }^{4}$ Faculty of Humanities and Social Sciences, University of Rijeka, Rijeka, Croatia
}

received: 9.3.2017;

revised: 23.5.2017;

accepted: 14.6 .2017

\section{SUMMARY}

Background: The aim of this study was to examine whether there is a difference in the dimensions of attachment and difference in emotional regulation between the group of female patients suffering from bulimia nervosa (BN) and the control group. We also wanted to examine whether emotional regulation has a mediating role in the relationship between dimensions of attachment and severity of BN symptoms.

Subjects and methods: The study included a total of 100 female participants from 15 to 25 years of age (M=20.40, SD=3.26). The clinical group consisted of 50 patients suffering from $B N$, and the control group consisted of 50 healthy female subjects.

Results: Female patients suffering from BN achieved higher scores in the dimensions of anxiety $\left(t_{98}=-5.12, p=0.00\right)$ and avoidance $\left(t_{98}=-4.30, p=0.00\right)$. Dimension of attachment related anxiety $(\beta=0.44, p=0.00)$ proved to be a statistically significant predictor of BN symptoms. Subjects of the clinical group also achieved significantly higher $\left(t_{98}=7.41, p=0.00\right)$ emotional dysregulation than participants of the control group. We also found that the mediation effect of emotional regulation on the association between anxiety and BN symptoms was statistically significant $\left(z^{\prime}=4.43, p=0.00\right)$.

Conclusions: Patients suffering from BN showed significantly higher levels of attachment related anxiety and avoidance as well as significantly higher level of difficulties in emotional regulation than healthy controls. Attachment anxiety proved to be a significant predictor of symptoms BN, suggesting that the attachment related anxiety is stronger correlate of BN symptoms than avoidance, and may represent a risk factor for more severe BN symptoms. It was also found that the relationship between attachment related anxiety and BN symptoms were mediated by emotional regulation.

Key words: bulimia nervosa - attachment anxiety - attachment avoidance - emotional regulation

\section{INTRODUCTION}

There is a basic assumption in clinical psychology and psychiatry that the quality of close relationships has a significant impact on mental health problems (Zachrisson \& Skårderud 2010). According to this assumption, attachment theory (Bowlby 1980) has become one of the most important theoretical frameworks for the understanding of general, as well as eating psychopathology. Through attachment relations human infants receive a sense of security from the primary caregiver, and repeated interactions with a caregiver become encoded in the implicit memory system, hence they develop into internal working models of attachment (Amini et al. 1996). Internal working models become the basis for consistent ways in which children and adults interact with the world, experience themselves and others, and regulate affect. These functions, especially affect regulation have implications on eating disorder psychopathology (Tasca \& Balfour 2014).

Originally, attachment was conceptualized in categorical terms of three categories: secure, anxious and avoidant (Hazan \& Shaver 1987), with avoidant later being divided into two categories (Bartholomew \&
Horowitz 1991). Recent evidence suggests that attachment is most accurately measured by dimensions rather than by categories (Fraley et al. 2000). Brennan et al. (1998) suggested that there are two fundamental dimensions with respect to adult attachment patterns; attachment related anxiety and attachment related avoidance. Attachment anxiety may develop when attachment figures are inconsistent or unpredictable. In an attempt to maintain an engagement with inconsistent caregivers, these children hyperactivate their attachment systems. This involves excitatory pathways that intensify negative emotional responses by keeping them active in working memory resulting in an up regulation of emotion (Shaver \& Mikulincer 2002). Attachment avoidance may develop when individuals perceive their primary attachment figure as rejecting or unavailable. In response, these individuals deactivate their attachment systems and defensively devalue their need for relationships. Thus, affective experiences are cut off from working memory, and this is accompanied by a downregulation of emotion (Shaver \& Mikulincer 2002).

Generally, bulimia nervosa (BN) has been associated with a high degree of Cluster B personality disorders (Cassin \& von Ranson 2005, Godt 2008) and associated 
manifestations of hyperactivation of attachment systems and poor emotion regulation, such as high impulsivity, affective instability, and disinhibition (Keel et al. 2007, Grilo 2002). Studies in young adults with BN have already demonstrated that higher attachment anxiety was significantly related to greater $\mathrm{BN}$ symptom severity (Cash \& Annis 2004, Illing et al. 2010). Research also demonstrated that individuals with BN display greater emotion dysregulation than controls (Harrison et al. 2010, Svaldi et al. 2012), and that higher levels of emotion dysregulation in $\mathrm{BN}$ are associated with greater levels of eating disorder psychopathology (Lavender et al. 2014, Svaldi et al. 2012). Similar results were also found in males suffering from $\mathrm{BN}$ (Fernández-Aranda et al. 2004, Sernec et al. 2015). Tasca et al. (2009) found that the association between attachment anxiety and ED symptoms was mediated by hyperactive affect regulation.

The purpose of this study was to examine whether there is a difference in the dimensions of attachment and difference in emotional regulation between the group of female patients suffering from $\mathrm{BN}$ and the control group. We also wanted to examine whether emotional regulation has a mediating role in the relationship between dimensions of attachment and severity of $\mathrm{BN}$ symptoms. It was hypothesized that the group of female patients suffering from $\mathrm{BN}$ will demonstrate higher attachment anxiety and attachment avoidance, as well as higher emotional dysregulation. It was also hypothesized that the association between attachment dimensions and BN symptoms was mediated by affect dysregulation.

\section{SUBJECTS AND METHODS}

\section{Subjects}

The study included a total of 100 female participants from 15 to 25 years of age $(M=20.40, S D=3.26)$. The clinical group consisted of 50 patients suffering from $\mathrm{BN}$, treated at University Hospital Center Zagreb, where in the symptoms do not last longer than 12 months. The control group consisted of 50 subjects that were matched with participants of clinical groups to the essential characteristics. The subjects were recruited into control group from School for Nurses Mlinarska, XVIII. Gymnasium Zagreb, and the Health Center Zagreb - West. Participants whose score was greater than or equal 2. on the SCOFF questionnaire were not included into control group.

\section{Measures}

SCOFF is questionnaire for screening participants with symptoms of anorexia nervosa and bulimia nervosa (Botella et al. 2013). It consists of five questions related to eating on which respondents answer "yes" or "no." Two or more "yes" suggests the existence of eating disorders. The sensitivity of the questionnaire for the existence of the $\mathrm{BN}$ confidence interval $92.6 \%-100.0 \%$ (Morgan et al. 1999).
Body Mass Index (BMI) was calculated from selfreports of height and weight. Selfreports of height and weight have been shown to be highly correlated with actual measures (Coates et al. 1978, Stunkard \& Albaum 1981).

Eating disorder inventory-2 (EDI-2) was developed by Garner (1991) to measure the behaviors and attitudes related to anorexia nervosa and bulimia nervosa. It comprises 91 items, and three subscales measuring eating behavior and specific mental pathology (drive for thinness, bulimia, and body dissatisfaction), and eight subscales assessing general psychopathology (ineffectiveness, perfectionism, interpersonal distrust, interoceptive awareness, maturity fear, asceticism, impulse regulation, and social insecurity). Responses are scored on a 6-point Likert scale and recoded into a 4-point scale, with a " 0 " assigned to the three least symptomatic responses and a "3" assigned the most symptomatic responses. The Cronbach $\alpha$ reliability index for the recorded 11 subscales were as follows: drive for thinness 0.95 ; bulimia 0.92 ; body dissatisfaction 0.93 ; ineffectiveness 0.90 ; perfectionism 0.80 ; interpersonal distrust 0.80 ; interoceptive awareness 0.92 ; maturity fears 0.86 ; asceticism 0.68 ; impulse regulation 0.82 ; and social insecurity 0.71 . The EDI-2 bulimia subscale was used as a measure of BN symptoms.

The Experiences in Close Relationships-Revised (ECR-R) (Fraley et al. 2000) questionnaire is a revised version of Experiences in Close Relationships (ECR) (Brennan et al. 1998) questionnaire. The questionnaire contains 36 items rated on a 7-point Likert-type scale where $1=$ strongly disagree and $7=$ strongly agree. The items are distributed in two subscales; attachmentrelated anxiety (i.e., the extent to which people are insecure vs. secure about the availability and responsiveness of close person) and attachment-related avoidance (i.e., the extent to which people are uncomfortable being close to others vs. secure depending on others). More research confirms the improvement of metric characteristics of the ECR-R in relation to the ECR (Esbjørn et al. 2015), and the stability of the twofactor structure (Sibley \& Liu 2004). Cronbach $\alpha$ reliability coefficient obtained in this study for anxiety subscale was 0.90 and for avoidance subscale was 0.92 .

Difficulties in Emotion Regulation Scale (DERS) was developed by Gratz \& Roemer (2004) to assess emotion dysregulation. The measure comprises 36 -items and provides a total score and six subscale scores: nonacceptance (nonacceptance of emotional states), strategies (limited access to adaptive emotion regulation skills), goals (difficulty with goal-directed behavior in the context of emotional distress), impulse (difficulty controlling behaviors when upset), clarity (lack of emotional clarity), and awareness (lack of emotional awareness). Items are rated on 5-point Likert-type scale and are summed such that higher scores indicate greater emotion dysregulation. The measure has demonstrated good validity and reliability in past research (Gratz \& 
Roemer 2004), including in studies with ED samples (e.g., Harrison et al. 2010, Racine \& Wildes 2013). The Cronbach $\alpha$ reliability index for the recorded 6 subscales were as follows: nonacceptance 0.90 , goals 0.89 , impulse 0.87 , awareness 0.78 , strategies 0.91 , clarity 0.86 , and for DERS total score 0.88 . The DERS total score was used as a measure of emotion regulation deficit.

\section{Statistical analysis}

To compare sociodemografical data among two groups we used Chi-square test or Fisher's exact test with Freeman-Halton extension for categorical data and t-test for continuous data. To evaluate the correlations between the variables we used Pearson correlation coefficient. To determine the relationship between the interval predictor and criterion variables were used multiple regression analysis. In order to test the existence of mediation influence were conducted hierarchical regression analysis and then testing the significance of a mediation effect with Sobel test. Statistical data processing is done using the software STATISTICA 12.7, and was used the level of significance of $5 \%$ $(\mathrm{p}<0.05)$ and $1 \%(\mathrm{p}<0.01)$.

\section{RESULTS}

\section{Comparison of sociodemographic characteristics}

Table 1 shows comparisons of sociodemographic characteristics of patients with $\mathrm{BN}$ and healthy controls (HC) and their families. Most of the participants within each of the groups $(28 \%)$ are employed, $26 \%$ of respondents attend gymnasium, 24\% attend university, 12\% attend tertiary vocational school, and the lowest percentage of participants within each of the groups are enrolled in some type of secondary vocational school (10\%).

According to Fisher's exact test we found a statistically significant association $(\mathrm{p}=0.01)$ between membership to clinical or control group and the amount of monthly family disposable income, with greater representation of families with below-average income in clinical group, and greater representation of families with average and above-average disposable income in the control group. The result of Fisher's exact test also indicates a statistically significant association between group membership and the level of education of mothers $(\mathrm{p}=0.00)$, as well as statistically significant association between group membership and education levels of the father $(p=0.00)$ with greater representation of parents with primary, secondary and higher education in clinical group and greater representation of parents with a university degree in the control group. T-test did not register statistically significant difference in BMI $\left(\mathrm{t}_{96}=0.06, \mathrm{p}=0.95\right)$ between the participants of clinical groups $(M=20.88, S D=3.49)$ and participants of the control group $(\mathrm{M}=20.92, \mathrm{SD}=3.50)$.

\section{Attachment dimensions}

Table 2 shows the differences between clinical and control group on the dimensions of attachment related anxiety and attachment related avoidance on ECR-R. We find a statistically significant difference between group results in the dimensions of anxiety $\left(\mathrm{t}_{98}=-5.12, \mathrm{p}=0.00\right)$ and avoidance $\left(\mathrm{t}_{98}=-4.30, \mathrm{p}=0.00\right)$, wherein the subjects

Table 1. Comparisons of sociodemographic characteristics and BMI of patients with $\mathrm{BN}$ and $\mathrm{HC}$ and their families

\begin{tabular}{|c|c|c|c|}
\hline & $\begin{array}{c}\mathrm{BN}(\mathrm{n}=50) \\
\mathrm{n}(\%)\end{array}$ & $\begin{array}{c}\mathrm{HC}(\mathrm{n}=50) \\
\mathrm{n}(\%)\end{array}$ & $\mathrm{p}$ \\
\hline \multicolumn{4}{|c|}{ Current educational and employment status } \\
\hline Secondary vocational school & $5(10)$ & $5(10)$ & \\
\hline Gymnasium & $13(26)$ & $13(26)$ & \\
\hline Tertiary vocational school & $6(12)$ & $6(12)$ & \\
\hline University & $12(24)$ & $12(24)$ & \\
\hline Employed & $14(28)$ & $14(28)$ & \\
\hline Household income & & & 0.01 \\
\hline Below average & $14(28)$ & $3(6)$ & \\
\hline Average & $31(62)$ & $38(76)$ & \\
\hline Above average & $5(10)$ & $8(16)$ & \\
\hline Mother's education level & & & 0.00 \\
\hline Primary school & $3(6)$ & $0(0)$ & \\
\hline High school & $30(60)$ & $22(44)$ & \\
\hline Tertiary vocational school & $12(24)$ & $6(12)$ & \\
\hline University & $5(10)$ & $22(44)$ & \\
\hline Father's education level & & & 0.00 \\
\hline Primary school & $2(4)$ & $0(0)$ & \\
\hline High school & $32(64)$ & $28(56)$ & \\
\hline Tertiary vocational school & $8(16)$ & $2(4)$ & \\
\hline University & $8(16)$ & $20(40)$ & \\
\hline BMI & $\mathrm{M}=20.88(\mathrm{SD}=3.49)$ & $\mathrm{M}=20.92(\mathrm{SD}=3.50)$ & 0.95 \\
\hline
\end{tabular}

BN - Bulimia nervosa patients; $\mathrm{HC}$ - Healthy controls; $\quad \mathrm{BMI}$ - Body mass index; Significance values are from Chi-square test or Fisher's exact test with Freeman-Halton extension for categorical data and t-test for continuous data 
of the clinical group achieved higher scores on both attachment dimensions. We also found statistically significant positive correlations between attachment related anxiety and $\mathrm{BN}$ symptoms $(\mathrm{r}=0.48, \mathrm{p}<0.01)$, as well as between attachment related avoidance and $\mathrm{BN}$ symptoms $(\mathrm{r}=0.39, \mathrm{p}<0.01)$ (Table 3$)$.

In order to test contribution of attachment dimensions to the explanation of variance in BN symptoms, while controlling the effect of socio-demographic variables we used hierarchical multiple regression - method enter. In the first block we entered family income, mother's education level and father's education level, as predictors. Regression model proved not to be statistically significant $(\mathrm{F}=0.48, \mathrm{p}=0.69)$ and it explained a total of $1.5 \%$ variance of BN symptoms (Table 4$)$. With the addition of attachment anxiety and attachment avoidance in the second block considerable predictive power was added to the model, increasing the amount of BN symptoms variability accounted for up to $26.7 \%$, and the model proved to be statistically significant $(\mathrm{F}=6.77, \mathrm{p}=0.00)$. Significance of the regression coefficients in multiple regression model indicates that the dimension of attachment related anxiety $(\beta=0.44$, $\mathrm{p}=0.00$ ) represents a statistically significant predictor of BN symptoms, while attachment related avoidance $(\beta=0.11, p=0.35)$ does not contribute significantly to the explanation of variance in $\mathrm{BN}$ symptoms.

\section{Emotional regulation}

Comparison of the DERS results is presented in Table 2. As expected, participants of the clinical group achieved significantly higher scores than participants of the control group on all scales of the DERS, as well as the DERS total score: nonacceptance $\left(\mathrm{t}_{98}=4.23, \mathrm{p}=0.00\right)$, goals $\left(\mathrm{t}_{98}=3.79, \mathrm{p}=0.00\right)$, impulse $\left(\mathrm{t}_{98}=6.62, \mathrm{p}=0.00\right)$, awareness $\left(\mathrm{t}_{98}=3.47, \mathrm{p}=0.00\right)$, strategies $\left(\mathrm{t}_{98}=7.75, \mathrm{p}=0.00\right)$, clarity $\left(\mathrm{t}_{98}=7.08, \mathrm{p}=0.00\right)$, DERS total $\left(\mathrm{t}_{98}=7.41, \mathrm{p}=0.00\right)$. The DERS total score, as a measure of emotion regulation deficit, was found to be statistically significantly positively correlated with $\mathrm{BN}$ symptoms $(\mathrm{r}=0.64$, $\mathrm{p}<0.01)$.

Table 2. Comparisons of ECR-R and DERS scores of patients with $\mathrm{BN}$ and healthy controls

\begin{tabular}{|c|c|c|c|c|c|c|c|}
\hline & \multicolumn{2}{|c|}{$\mathrm{BN}(\mathrm{n}=50)$} & \multicolumn{2}{|c|}{$\mathrm{HC}(\mathrm{n}=50)$} & \multicolumn{3}{|c|}{ t-test } \\
\hline & $\mathrm{M}$ & SD & $\mathrm{M}$ & SD & $\mathrm{t}$ & df & $\mathrm{p}$ \\
\hline \multicolumn{8}{|l|}{ ECR-R } \\
\hline Anxiety & 4.56 & 1.20 & 3.21 & 1.41 & -5.12 & 98 & 0.00 \\
\hline Avoidance & 3.59 & 1.39 & 2.41 & 1.33 & -4.30 & 98 & 0.00 \\
\hline \multicolumn{8}{|l|}{ DERS } \\
\hline Nonaccept & 18.60 & 7.14 & 13.22 & 5.44 & 4.23 & 98 & 0.00 \\
\hline Goals & 18.20 & 5.22 & 14.30 & 5.05 & 3.79 & 98 & 0.00 \\
\hline Impulse & 19.92 & 6.29 & 12.60 & 4.63 & 6.62 & 98 & 0.00 \\
\hline Awareness & 18.68 & 5.16 & 15.52 & 3.85 & 3.47 & 98 & 0.00 \\
\hline Strategies & 29.16 & 7.88 & 17.62 & 6.96 & 7.75 & 98 & 0.00 \\
\hline Clarity & 16.52 & 5.01 & 10.10 & 3.98 & 7.08 & 98 & 0.00 \\
\hline DERS Total & 121.08 & 27.59 & 83.36 & 23.06 & 7.41 & 98 & 0.00 \\
\hline
\end{tabular}

$\mathrm{BN}$ - Bulimia nervosa patients; $\mathrm{HC}-$ Healthy controls

Table 3. Correlations among variables anxiety, avoidance, emotional regulation and BN symptoms

\begin{tabular}{lcccc}
\hline & Anxiety & Avoidance & Emotional regulation & BN symptoms \\
\hline Anxiety & 1 & $0.63^{*}$ & $0.64^{*}$ & $0.48^{*}$ \\
Avoidance & & 1 & $0.45^{*}$ & $0.39^{*}$ \\
Emotional regulation & & & 1 & $0.64^{*}$ \\
BN symptoms & & & & 1 \\
\hline
\end{tabular}

$\mathrm{BN}-$ Bulimia nervosa; $\mathrm{N}=100 ; \quad * \mathrm{p}<0.01$

Table 4. Summary of hierarchical regression analysis for attachment related variables predicting BN symptoms with controlling of sociodemographic variables

\begin{tabular}{|c|c|c|c|c|c|c|c|c|c|}
\hline \multirow[b]{2}{*}{ Step } & \multirow[b]{2}{*}{ Variables } & \multirow[b]{2}{*}{$\mathrm{B}$} & \multirow[b]{2}{*}{$\beta$} & \multirow[b]{2}{*}{$\mathrm{t}$} & \multirow[b]{2}{*}{$\mathrm{p}$} & \multicolumn{4}{|c|}{ Regression model } \\
\hline & & & & & & $\mathrm{R}$ & $\mathrm{R}^{2}$ & $\mathrm{~F}$ & $\mathrm{p}$ \\
\hline \multirow{3}{*}{1.} & Household income & -0.92 & -0.07 & -0.63 & 0.52 & \multirow{3}{*}{0.12} & \multirow{3}{*}{0.1} & \multirow{3}{*}{0.48} & \multirow{3}{*}{0.69} \\
\hline & Mother's education level & -0.89 & -0.11 & -0.91 & 0.36 & & & & \\
\hline & Father's education level & 0.85 & 0.10 & 0.85 & 0.39 & & & & \\
\hline \multirow{5}{*}{2.} & Household income & 0.88 & 0.06 & 0.66 & 0.51 & \multirow{5}{*}{0.51} & \multirow{5}{*}{0.26} & \multirow{5}{*}{6.77} & \multirow{5}{*}{0.0} \\
\hline & Mother's education level & -0.84 & -0.10 & -0.97 & 0.33 & & & & \\
\hline & Father's education level & 0.61 & 0.79 & 0.70 & 0.48 & & & & \\
\hline & Anxiety & 2.13 & 0.44 & 3.58 & 0.00 & & & & \\
\hline & Avoidance & 0.52 & 0.11 & 0.92 & 0.35 & & & & \\
\hline
\end{tabular}

$\mathrm{N}=100 ; \quad \mathrm{B}-$ unstandardized regression coefficient; $\quad \beta$-standardized regression coefficient

$\mathrm{R}$ - coefficient of multiple correlation; $\mathrm{R}^{2}$ - coefficient of multiple determination 
Table 5. Hierarchical regression analysis for testing mediation effect of emotional regulation on the relationship between anxiety and BN symptoms

\begin{tabular}{|c|c|c|c|c|c|c|c|c|}
\hline \multirow[b]{2}{*}{ Step } & \multirow[b]{2}{*}{ Variable } & \multirow[b]{2}{*}{$\beta$} & \multirow[b]{2}{*}{$\mathrm{t}$} & \multirow[b]{2}{*}{$\mathrm{p}$} & \multicolumn{4}{|c|}{ Regression model } \\
\hline & & & & & $\mathrm{R}$ & $\mathrm{R}^{2}$ & $\mathrm{~F}$ & $\mathrm{p}$ \\
\hline 1. & Anxiety* & 0.48 & 5.47 & 0.00 & 0.48 & 0.23 & 29.95 & 0.00 \\
\hline 2. & Anxiety ** & 0.64 & 8.37 & 0.00 & 0.64 & 0.41 & 70.13 & 0.00 \\
\hline 3. & $\begin{array}{l}\text { Anxiety * } \\
\text { Emotion regulation }\end{array}$ & $\begin{array}{l}0.11 \\
0.57\end{array}$ & $\begin{array}{l}1.11 \\
5.70\end{array}$ & $\begin{array}{l}2.66 \\
0.00\end{array}$ & 0.65 & 0.42 & 36.09 & 0.00 \\
\hline
\end{tabular}

\section{Emotional regulation as a potential mediator in the relationship between attachment anxiety and $B N$ symptoms}

The nature of the relationship between the variables we tried to explain with the mediation relationship. In order to examine the impact of mediation effect of emotion regulation we used a four step approach proposed by Baron \& Kenny (1986) in which several regression analyses were conducted. The results are shown in Table 5. In the first step attachment anxiety has been introduced as a predictor variable into the equation with the severity of $\mathrm{BN}$ symptoms as a criterion. Unique contribution of anxiety in explaining the variance of $\mathrm{BN}$ symptoms proved to be statistically significant $(\beta=0.48$, $\mathrm{t}=5.47, \mathrm{p}=0.00$ ), and it explained $23 \%$ of the variance. In the second step anxiety has been introduced as a predictor and emotion regulation as a criterion. The contribution of anxiety in explaining the variance of emotional regulation also showed to be statistically significant $(\beta=0.64, \mathrm{t}=8.37, \mathrm{p}=0.00)$ with $41 \%$ of variance explained. In the third step, we introduced anxiety and emotional regulation as predictors and severity of $\mathrm{BN}$ symptoms as a criterion. After introduction of the emotion regulation contribution of anxiety in explaining the variance of BN symptoms became statistically insignificant $(\beta=0.11, t=1.11, p=2.66)$, whereas contribution of emotion regulation remained statistically significant $(\beta=0.57, t=5.70, p=0.00)$, which supports full mediation. Sobel test indicates that the mediation effect of emotional regulation on the association between anxiety and $\mathrm{BN}$ symptoms was statistically significant $\left(\mathrm{z}^{\prime}=4.43\right.$, $\mathrm{p}=0.00)$. All conditions for mediation are met and the mediation role of emotional regulation between anxiety and severity of BN was confirmed.

\section{DISCUSSION}

Of the observed socio-demographic characteristics we recorded that participants suffering from BN come from families with below-average income and (tend to) have parents with lower education level. According to research conducted by Goeree et al. (2011) the poorest girls exhibit a $32 \%$ increase of symptoms of $\mathrm{BN}$ (relative to the mean of the EDI bulimia subscale) when compared to middle class girls, and a $40 \%$ increase when compared to wealthier peers. These findings stand in stark contrast to the popular conceptions about eating disorders. National Longitudinal Study of Adolescent
Health (Harris et al. 2009) suggests girls in a high income households with highly educated parents are almost twice as likely to be diagnosed with an eating disorders relative to an average girl, indicating that the popular conception is consistent only with who is diagnosed with an eating disorder, suggesting dramatic differences in diagnosis across income classes. Results have the implications that greater outreach for $\mathrm{BN}$ should be made to individuals from low income families (Goeree et al. 2011). Our results also suggest that there is no statistically significant difference in BMI between the participitants of clinical and control group which is in line with expectations, as it is known that patients suffering from $\mathrm{BN}$ are usually not markedly thin, and can be average or above-average weight. For that very reason their disease often goes unnoticed, unlike patients suffering from anorexia nervosa. According to Hudson et al. (2007) $65.3 \%$ of patients suffering from $\mathrm{BN}$ have body weight within the average, with a BMI between 18.5 and 29.9 , while only $3.5 \%$ have lower body weight with a BMI of less than 18.5 .

Patients suffering from BN showed higher attachment related anxiety and avoidance. The findings are consistent with the hypothesis according to which we expected a higher level of anxiety and avoidance in women with BN, suggesting that patients with BN experience close relations through constant vigilance, a sense of fear and worries of possible rejection and abandonment (anxiety), and the discomfort associated with closeness (avoidance), which is defined as fearful avoidant attachment style (Bartholomew \& Horowitz 1991). This style indicates a sense of unworthiness combined with an expectation that others will be negatively disposed. By avoiding close involvement with others, this style enables people to protect themselves against anticipated rejection by others. In contrast to $\mathrm{BN}$ patients healthy participants reported low anxiety and low avoidance indicative of secure attachment. Our findings are consistent with the findings of research conducted by Evans \& Wertheim (2005).

Even though both attachment related anxiety and attachment related avoidance were significantly associated with BN symptoms, in multivariate model only attachment anxiety proved to be a significant predictor of symptoms BN, suggesting that the attachment related anxiety is stronger correlate of BN symptoms and plays a more important role in prediction of $\mathrm{BN}$ symptoms than avoidance, and furthermore it may represent a risk factor for more severe $\mathrm{BN}$ symptoms. Based on the 
literature on personality and eating disorders, Tasca \& Balfour (2014) speculate that individuals who binge and purge (i.e. who have $\mathrm{BN}$ ) may show greater attachment anxiety associated with affect dysregulation, whereas those who engage in dietary restriction (i.e. who have AN) may show greater avoidance characterized by down-playing of affect. Attachment anxiety is also indicated by a hypervigilant, anxious attention seeking focus on attachment figures and relationships, failure to detach from psychological pain, and hyperactivation of negative thoughts and emotions (Shaver \& Mikulincer 2002). Studies in young adults with BN have already demonstrated that higher attachment anxiety was significantly related to greater $\mathrm{BN}$ symptom severity and poorer treatment outcome (Cash \& Annis 2004, Illing et al. 2010). In the analysis we also controlled sociodemographic variables, whose influence was statistically insignificant.

At the DERS total score, which was used as a measure of emotion regulation deficit, as expected, patients with $\mathrm{BN}$ achieved significantly higher scores compared to healthy subjects in the control group. In addition to the DERS total score, as most deficient aspects of emotional regulation stands out the lack of emotional clarity (clarity), limited access to adaptive emotion regulation skills (strategies) and difficulty controlling behaviors when upset (impulse). The results are similar to findings Lavender et al. (2014), which in addition to the above aspects also single out nonacceptance of emotional states (nonacceptance). Overall emotional regulation difficulties (DERS total score) also represent a statistically significant predictor of $\mathrm{BN}$ symptoms. The obtained results are consistent with the findings of previous studies suggesting that patients suffering from eating disorders, including BN, reported a higher level of emotional regulation difficulty (Harrison et al. 2010, Svaldi et al. 2012), as well as consistent with theoretical models to which the emotional regulation difficulties contribute to psychopathology of eating disorders, and acting as inappropriate strategies to manage their own emotions (Wildes et al. 2010, Haynos \& Fruzzetti 2011, Wonderlich et al. 2014).

Furthermore, the nature of the relationship between attachment related anxiety, emotional regulation and $\mathrm{BN}$ symptoms we tried to explain with the mediation relationship. With conducted hierarchical regression analyses we proved that the relationship between attachment related anxiety and $\mathrm{BN}$ symptoms were mediated by emotional regulation. Our findings support the role of insecure attachment organisation in manifestation of $\mathrm{BN}$ symptoms, wherein a significant role is played by emotional regulation. Based on our results and the literature (e.g. Tasca \& Balfour 2014, Cassin \& Ranson 2005, Hickman 1998) it is plausible to conclude that early attachment relations are seen to be crucial in the acquisition of skills of emotion regulation, in a way that attachment related anxiety may contribute to development of emotion regulation deficits, which in turn may result in expression of BN symptoms.

\section{CONCLUSIONS}

It was found that patients suffering from $\mathrm{BN}$ showed significantly higher levels of attachment related anxiety and avoidance than control group subjects. In multivariate model only attachment anxiety proved to be a significant predictor of symptoms $\mathrm{BN}$, suggesting that the attachment related anxiety is stronger correlate of BN symptoms and plays a more important role in prediction of $\mathrm{BN}$ symptoms than avoidance, and furthermore it may represent a risk factor for more severe $\mathrm{BN}$ symptoms. Patients suffering from $\mathrm{BN}$ also showed significantly higher level of difficulties in emotional regulation than healthy controls. It was also found that the relationship between attachment related anxiety and BN symptoms were mediated by emotional regulation.

\section{Acknowledgements: None.}

\section{Conflict of interest: None to declare.}

\section{Contribution of individual authors:}

Study conception and design: Trpimir Jakovina, Ivan Begovac;

Data collection: Maja Crnković Batista, Andrea Ražić Pavičić, Iva Žurić Jakovina, Trpimir Jakovina;

Statistical analysis and interpretation of the data: Trpimir Jakovina, Maja Crnković Batista;

Writing of the manuscript: Trpimir Jakovina, Andrea Ražić Pavičić, Iva Žurić Jakovina;

Manuscript drafts review: Ivan Begovac.

\section{References}

1. Amini F, Lewis T, Lannon R, Louie A, Baumbacher G, McGuinness T et al.: Affect, attachment, memory: Contributions toward psychobiologic integration. Psychiatry 1996; 59:213-39

2. Baron RM \& Kenny DA: The Moderator-Mediator Variable Distinction in Social Psychology Research: Conceptual, Strategic and Statistical Considerations. J Pers Soc Psychol 1986; 51:1173-82

3. Bartholomew K\& Horowitz LM: Attachment styles among young adults: a test of four-category model. J Pers Soc Psychol 1991; 61:226-44

4. Botella J, Sepulveda AR, Huang $H$ \& Gambara $H: A$ meta-analysis of the diagnostic accuracy of the SCOFF. Span J Psychol 2013; 16:e92:1-8

5. Bowlby J: Attachment and loss. Basic Books, New York, 1980

6. Brennan KA, Clark $C L \&$ Shaver PR: Self-report measurement of adult romantic attachment: An integrative overview. In Simpson JA \& Rholes WS (eds): Attachment theory and close relationships, 46-76. Guilford Press, New York, 1998

7. Cash TF \& Annis NM: Body image in an interpersonal context: adult attachment, fear of intimacy and social anxiety. J Soc Clin Psychol 2004; 23:89-103

8. Cassin SE \& von Ranson KM: Personality and eating disorders: A decade in review. Clin Psychol Rev 2005; 25:895-916 
9. Coates $T$, Jeffery $R$ \& Wing $R$ : The relationship between person's relative body weights and the quality and quantity of food stored in their homes. Addict Behav 1978; 3:179-85

10. Esbjørn BH, Breinholst S, Niclasen J, Skovgaard LF, Lange $K \&$ Reinholdt-Dunne ML: Identifying the bestfitting factor structure of the experience of close relationsrevised in a Scandinavian example. PloSOne 2015; 10:e0137218

11. Evans L \& Wertheim EH: Attachment Styles in Adult Intimate Relationships: Comparing Women with Bulimia Nervosa Symptoms, Women with Depression and Women with No Clinical Symptoms. Eur Eat Disord Rev 2005; 13:285-93

12. Fernández-Aranda F, Aitken A, Badia I, Giménez D, Solano R, Collier $D$ et al.: Personality and psychopathological traits of males with an eating disorder. Eur Eating Disorders Rev 2004; 12:367-74

13. Fraley RC, Waller $N G$ \& Brennan KA: An item-response theory analysis of self-report measures of adult attachment. J Pers Soc Psychol 2000; 78:350-65

14. Garner DM: EDI-2. Eating disorder inventory-2. Professional manual. Psychological Assessment Resources, Odessa, FL, 1991

15. Goeree MS, Ham JC \& Iorio D: Race, Social Class, and Bulimia Nervosa. IZA Discussion Paper No. 5823. 2011. Available at http://ssrn.com/abstract $=1877636$

16. Gratz KL \& Roemer L: Multidimensional Assessment of Emotion Regulation and Dysregulation: Development, Factor Structure, and Initial Validation of the Difficulties in Emotion Regulation Scale. J Psychopathol Behav Assess 2004; 26:41-54

17. Godt K: Personality disorders in 545 patients with eating disorders. Eur Eat Disord Rev 2008; 16:94-9

18. Grilo CM: Recent research of relationships among eating disorders and personality disorders. Curr Psychiatry Rep 2002; $4: 18-24$

19. Harris KM, Halpern CT, Whitsel E, Hussey J, Tabor J, Entzel P et al.: The National Longitudinal Study of Adolescent Health: Research design. UNC Carolina Population Centre 2009. Available at www.cpc.unc.edu/projects/addhealth/design

20. Harrison A, Sullivan K, Tchanturia $K$ \& Treasure J: Emotional functioning in eating disorders: attentional bias, emotion recognition and emotion regulation. Psychol Med 2010; 40:1887-97

21. Haynos AF \& Fruzzetti AE: Anorexia Nervosa as a Disorder of Emotion Dysregulation: Evidence and Treatment Implications. Clin Psychol Sci Prac 2011; 18:183-202

22. Hazan C\& Shaver PR: Romantic love conceptualized as an attachment process. J Pers Soc Psychol 1987; 59:270-80

23. Hickman K: Adult attachment, bulimia nervosa and relationship satisfaction. University of canterbury. Thesis, 1998

24. Hudson JI, Hiripi E, Pope HG \& Kessler RC: The Prevalence and Correlates of Eating Disorders in the
National Comorbidity Survey Replication. Biol Psychiatry 2007; 61:348-58

25. Illing V, Tasca GA, Balfour L \& Bissada H: Attachment insecurity predicts eating disorder symptoms and treatment outcomes in a clinical sample of women. J Nerv Ment Dis 2010; 198:653-9

26. Keel PK, Wolfe BE, Liddle RA, De Young KP \& Jimerson $D C$ : Clinical features and physiological response to a test meal in purging disorder and bulimia nervosa. Arch Gen Psychiatry 2007; 64:1058-66

27. Lavender JM, Wonderlich SA, Peterson CB, Crosby RD, Engel SG, Mitchell JE et al.: Dimensions of emotion dysregulation in bulimia nervosa. Eur Eat Disord Rev $2014 ; 22: 212-6$

28. Morgan JF, Reid F \& Lacey JH: The SCOFF questionnaire: assessment of a new screening tool for eating disorders. BMJ: Br Med J 1999; 319:1467-8

29. Racine SE \& Wildes JE: Emotion dysregulation and symptoms of anorexia nervosa: the unique roles of lack of emotional awareness and impulse control difficulties when upset. Int J Eat Disord 2013; 46:713-20

30. Sernec K, Mrevlje GV, Čarapič J, Weber U \& Zalar B: Male anorexia and bulimia nervosa: disorder symptoms and impulsive behaviour during hospital treatment and one year follow-up period. Psychiat Danub 2015; 27:242-9

31. Shaver PR \& Mikulincer M: Attachment-related psychodynamics. Attach Hum Dev 2002; 4:133-61

32. Sibley CG \& Liu JH: Short-term temporal stability and factor structure of the revised experiences in close relationships (ECR-R) measure of adult attachment. Pers Individ Dif 2004; 36:969-75

33. Stunkard AJ \& Albaum M: The accuracy of self-reported weights. Am J Clin Nutr 1981; 34:1593-9

34. Svaldi J, Griepenstroh J, Tuschen-Caffier B \& Ehring T: Emotion regulation deficits in eating disorders: A marker of eating pathology or general psychopathology? Psychiatry Res 2012; 197:103-11

35. Tasca GA, Szadkowski L, Illing V, Trinneer A, Grenon R, Demidenko $N$ et al.: Adult attachment, depression, and eating disorder symptoms: The mediating role of affect regulation strategies. Pers Individ Dif 2009; 47:662-7

36. Tasca $G$ \& Balfour L: Attachment and eating disorders: a review of current research. Int J Eat Disord 2014; 47:710-7

37. Zachrisson HD \& Skårderud F: Feelings of Insecurity: Review of Attachment and Eating Disorders. Eur Eat Disord Rev 2010; 18:97-106

38. Wildes JE, Ringham RM \& Marcus MD: Emotion avoidance in patients with anorexia nervosa: initial test of a functional model. Int J Eat Disord 2010; 43:398-404

39. Wonderlich SA, Peterson CB, Crosby RD, Smith T, Klein $M$, Mitchell JE et al.: A randomized controlled comparison of integrative cognitive-affective therapy (ICAT) and enhanced cognitive-behavioral therapy (CBT-E) for bulimia nervosa. Psychol Med 2014; 44:543-53

Correspondence:

Trpimir Jakovina, MD, PhD

Department of Psychological Medicine, University Hospital Center Zagreb

Kispaticeva 12, 10000 Zagreb, Croatia

E-mail: trpimir.jakovina@gmail.com 